\title{
Characterization and Photocatalytic Performance of Potassium-Doped Titanium Oxide Nanostructures Prepared via Wet Corrosion of Titanium Microspheres
}

\author{
So Yoon Lee ${ }^{1}$, Jie Zhang ${ }^{1}$, Lee-Woon Jang ${ }^{1}$, Zhihong Zhang ${ }^{1}$, Yujie Guo ${ }^{1}$, Samir Salameh², \\ Sanghoon Kim ${ }^{3}$, Dong Ick Son ${ }^{4}$, Vijay Shankar Rangasamy ${ }^{5}$, Savitha Thayumanasundaram ${ }^{5}$, \\ Jean-Pierre Locquet ${ }^{5}$, and Jin Won Seo ${ }^{1, *}$ \\ ${ }^{1}$ Department of Materials Engineering, KU Leuven, B-3001 Leuven, Belgium \\ ${ }^{2}$ Institut für Werkstofftechnik, Universität Bremen, D-28359 Bremen, Germany \\ ${ }^{3}$ Department of Materials Science and Engineering, Yonsei University, Seoul 120-749, Republic of Korea \\ ${ }^{4}$ Soft Innovative Materials Research Center, Korea Institute of Science and Technology, Wanju, 565-90, Republic of Korea \\ ${ }^{5}$ Department of Physics, KU Leuven, B-3001 Leuven, Belgium
}

\begin{abstract}
Potassium doped titanium oxide $\left(\mathrm{KTiO}_{x}\right)$ nanowires were prepared by the wet corrosion process (WCP) and their photocatalytic effects were systematically characterized. For the synthesis of $\mathrm{KTiO}_{x}$, the potassium hydroxide concentration of the WCP was varied in order to obtain nanostructures with different surface area and surface charge. Structural and crystalline properties of $\mathrm{KTiO}_{x}$ were studied by means of X-ray diffraction, scanning and transmission electron microscopy. Chemical composition was determined by X-ray fluorescence and energy-dispersive X-ray analysis. Photocatalytic performance was investigated as a function of the surface area, $\mathrm{pH}$, and crystalline structures by studying the degradation of methylene blue, cardiogreen, and azorubine red dyes upon UV irradiation. The negatively charged crystalline $\mathrm{KTiO}_{x}$ nanostructures with high surface area showed significantly higher photocatalytic degradation compared to their $\mathrm{TiO}_{x}$ counterpart. They also showed high efficiency for recovery and re-use. Annealing $\mathrm{KTiO}_{x}$ nanostructures improved structural properties leading to well-ordered layered structures and improved photocatalysis. However, annealing at temperatures higher than $600{ }^{\circ} \mathrm{C}$ yielded formation of rutile grains at the surface of nanowires, significantly affecting the photocatalytic performance. We believe that $\mathrm{KTiO}_{x}$ nanostructures produced by WCP are very promising for photocatalysis, especially due to their high photocatalytic efficiency as well as their potential for re-use and durability.
\end{abstract}

Keywords: $\mathrm{KTiO}_{x}$, Titanium Core Shell, Nanostructures, Photocatalysis, Wet Corrosion Process.

\section{INTRODUCTION}

Titanium (Ti)-based materials have widely been studied because of its abundance, low cost, excellent chemical stability, environmental benignity, high photocatalytic activity and antimicrobial properties. Especially, titanium oxide $\left(\mathrm{TiO}_{x}\right)$ materials have attracted considerable interests in many fields of research including photovoltaics and photocatalysis. ${ }^{1-6}$ Generally, when $\mathrm{TiO}_{2}$ is exposed to adequate photon energy of $<400 \mathrm{~nm}$, electron-hole pairs are generated on the surface. ${ }^{7-9}$ For the photocatalytic

*Author to whom correspondence should be addressed. application, these electron-hole pairs react with target molecules and degrade them. Commonly, monodispersed $\mathrm{TiO}_{2}$ nanoparticles and nanowires have extensively been studied because of their large surface area ${ }^{10-13}$ and strong light absorption. ${ }^{14-16}$ In addition, the photocatalytic efficiency could be enhanced by controlling adsorptiondesorption process via surface charges by changing $\mathrm{pH}$ or by applying alkaline doping. ${ }^{17-19}$ In particular, for K-doped $\mathrm{KTiO}_{x}$, the $\mathrm{K}$ doping promoted the stabilization of the anatase phase and also yielded higher efficacy of photocatalytic activity. ${ }^{20-22}$ Recently, the wet corrosion process (WCP) was applied to $\mathrm{Ti}$ metal substrates and a network of $\mathrm{KTiO}_{x}$ nanowires could be obtained on the metal 
surface. ${ }^{19,23,24}$ The WCP relies on potassium hydroxide $(\mathrm{KOH})$ treatment of $\mathrm{Ti}$ metal and has demonstrated high efficiency and high reproducibility in producing nanostructured surface with a high surface area and with varying potassium doping. The produced $\mathrm{KTiO}_{x}$ nanostructures showed high photocatalytic performances ${ }^{19,25}$ and could also successfully be used in dye-sensitized solar cells. ${ }^{26}$

The WCP is a simple one-step synthesis method at room-temperature without any supplementary treatments. ${ }^{19,23,24,27}$ The formation of $\mathrm{KTiO}_{x}$ nanowires is directly affected by the solution concentration, ${ }^{19}$ which also changes the $\mathrm{K}$ content in the nanostructures formed on the surface. Simultaneously, the surface area as well as the photocatalytic activity scales with the $\mathrm{KOH}$ concentration. Thus, the WCP is a promising method for the efficient and well-tunable production of $\mathrm{KTiO}_{x}$ nanostructures. So far, the basic principle of WCP was studied and a few applications of $\mathrm{KTiO}_{x}$ nanostructures have been reported, while a more detailed characterization is missing.

In this work, we synthesized $\mathrm{KTiO}_{x}$ nanowires on $\mathrm{Ti}$ microspheres by the WCP. The influence of the surface area and the effect of the surface charge were investigated. Structural and chemical evolution of $\mathrm{KTiO}_{x}$ were studied as a function of the annealing temperature. Additionally, the photocatalytic performance was derived from degradation of three organic dyes: methylene blue (MB), cardiogreen (CG) and azorubine red (AR), which represent potential pollutants in colored waste water. The negatively charged $\mathrm{KTiO}_{x}$ annealed at $600{ }^{\circ} \mathrm{C}$ showed the highest catalytic activity in all three tested dyes. These nanostructures are also highly suitable for recycling and re-use, especially for MB dyes a high recovery performance of about $97 \%$ was measured.

\section{EXPERIMENTAL DETAILS}

Ti microspheres (purity $>99.8 \%$, diameter of 125-250 $\mu \mathrm{m}$ ) were purchased from ChemPUR in Germany. ${ }^{19}$ Ti particles were soaked in $5 \mathrm{~mL} \mathrm{KOH}$ solution with concentration of $1,5,10,15,20$, and $25 \mathrm{~mol} / \mathrm{L}$ at room temperature for 24 hours. After this WCP step of the $\mathrm{KOH}$ treatment, all particles were washed with deionized water and dried. These particles contained a $\mathrm{Ti}$ core and a shell of $\mathrm{KTiO}_{x}$ nanowire forming a network. Subsequently, the particles were annealed at 300, 450, 600 and $750{ }^{\circ} \mathrm{C}$ for 2 hours in an oxygen-rich furnace (Carbolite GSM furnace 3216) to study their crystalline structure as a function of the annealing temperature.

Scanning electron microscope (SEM) combined with a focused ion beam (FIB, Dual Beam FEI Nova 600 NanoLab) was used to measure the surface structure, shape and size of $\mathrm{KTiO}_{x}$. For identification and visualization of the $\mathrm{KTiO}_{x}$ shell and Ti core structure, the WCP treated particles were sliced by FIB with $30 \mathrm{kV}$ Ga-ions, and cross-sectional parts were analyzed by energy-dispersive
X-ray (EDX, EDAX) spectroscopy. X-ray fluorescence (XRF, Philips PW2400, source: $50 \mathrm{kV}, 40 \mathrm{~mA}$ ) was measured for the quantitative elemental analysis. Transmission electron microscopy (TEM) and scanning transmission electron microscopy (STEM) were carried out using a probe-lens aberration-corrected microscope ARM200F (JEOL) equipped with a cold-field emission gun and the large-angle EDX spectrometer (Centurio, JEOL). For these measurements, a few spheres were glued directly on a half $\mathrm{Cu}$ grid (100 mesh, Agar Scientific).

Surface area analysis was performed by using NOVA 300E (Quantachrome), which estimates the surface area by nitrogen adsorption behaviors. The surface area was calculated based on the Brunauer-Emmett and Teller (BET) theory. Zeta potentials were measured by using an electrophoretic light scattering spectrophotometer in order to analyze the surface charge of the $\mathrm{KTiO}_{x}$ shell after treating at various conditions of $\mathrm{pH}$. A quartz cell was used to measure the electrophoretic mobility of polystylene latex reference particles. The $\mathrm{pH}$ value was adjusted using aqueous solution of $\mathrm{NaOH}$ and $\mathrm{HCl}$.

In order to evaluate the photocatalytic activity of the $\mathrm{KTiO}_{x}, 0.1 \mathrm{~g}$ of particles was taken and mixed with $2 \mathrm{ml}$ of MB (10 mg/L), CG (10 mg/L) and AR (10 mg/L) dye solutions separately under UV irradiation $(320 \sim 390 \mathrm{~nm}$, $159 \times 229 \mathrm{~mm}$ lamp) with $10 \mathrm{~cm}$ working distance. During the UV exposure, the solutions were stirred continuously. However, experiments performed without stirring didn't show any significant difference. After UV irradiation, the photocatalytic activity was evaluated by collecting the UV-Vis absorption spectra (Tecan, Model infinite M2000 PRO) of the solution. The recycle and re-use potential of $\mathrm{KTiO}_{x}$ nanostructures were evaluated by collecting a series of repeated photocatalytic reaction experiments under the same condition as described above. Deionized water, ethanol and iso-propanol were used for rinsing the $\mathrm{KTiO}_{x}$ after each treatment. The degradation efficiency was recorded after each cycle.

\section{RESULTS AND DISCUSSION}

\subsection{Morphology of the Synthesized $\mathrm{KTiO}_{x}$}

The resulting surface morphology strongly depended on the concentration of the treating $\mathrm{KOH}$ solution. Representative surface images of pristine Ti particles and $\mathrm{KOH}$ treated Ti particles are shown in Figure 1 . The $1 \mathrm{~mol} / \mathrm{L}$ and $15 \mathrm{~mol} / \mathrm{L} \mathrm{KOH}$ treated $\mathrm{Ti}$ particles showed the smallest and the largest surface areas, respectively. For concentrations below $20 \mathrm{~mol} / \mathrm{L}$, elongated nanowires with diameter of $10 \sim 100 \mathrm{~nm}$ and length of several tens of micrometers were observed. This result is very comparable with our previous results obtained on Ti plates. ${ }^{19}$ Thus, WCP enables nanostructures fabrication starting from various Ticontaining materials regardless of the shape of the material. In the cross-sectional image of Figure 1(d), the Ti core 

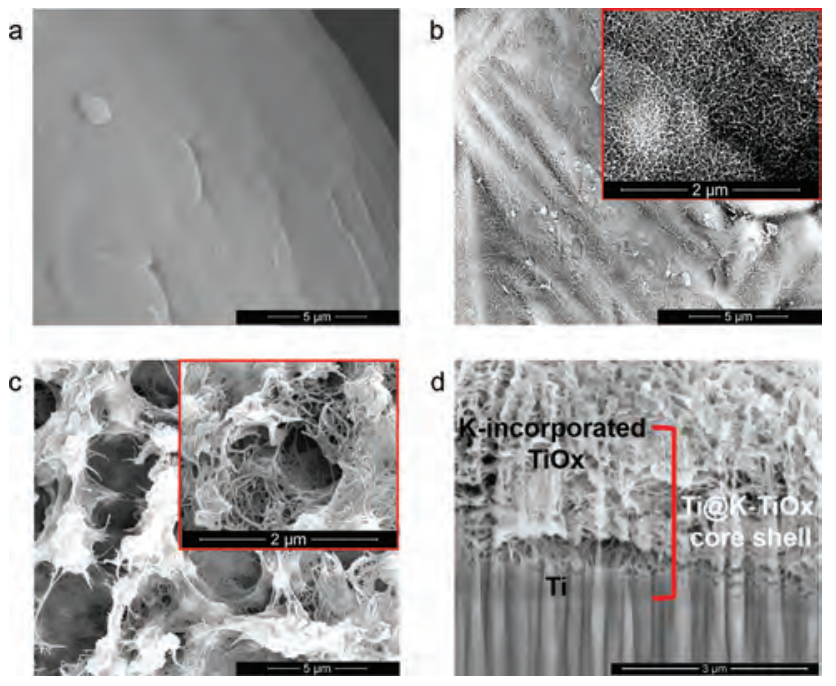

Figure 1. SEM images of (a) a Ti particle, (b) a $1 \mathrm{~mol} / \mathrm{L} \mathrm{KOH}$ treated Ti particle, and (c) a $15 \mathrm{~mol} / \mathrm{L} \mathrm{KOH}$ treated Ti particle at RT for 24 hours. The respective insets present enlarged images of the surface structures. (d) The cross-section image of a $15 \mathrm{~mol} / \mathrm{L} \mathrm{KOH}$ treated Ti particle reveals the interface area between the $\mathrm{KTiO}_{x}$ shell and the Ti core. The vertical striations originate from the FIB etching due to the curtaining effect.

and porous $\mathrm{KTiO}_{x}$ shell can clearly be seen. The total shell thickness was approximately $5 \mu \mathrm{m}$.

\subsection{Chemical Analysis of the $\mathrm{KTiO}_{x}$ Nanostructures}

EDX measurements performed on the cross-sectioned interface between the $\mathrm{Ti}$ core and the $\mathrm{KTiO}_{x}$ shell clearly confirmed the K doping (Fig. 2). The shell area (Fig. 2(a)) with the nanowire networks resulted in clear EDX peaks of $\mathrm{K}(3.31 \mathrm{keV}$ and $0.26 \mathrm{keV})$ and $\mathrm{O}(0.52 \mathrm{keV})$ whereas these peaks significantly decreased when moving the electron beam towards the Ti core (Fig. 2(b)), and completely disappeared in the core area. The color-coded EDX map presented in the inset of Figure 2(a) illustrates that the interface is not abrupt and that a transition area exists in the range of several micrometers. Figure 2(c) shows a TEM image of the $\mathrm{KTiO}_{x}$ nanowires with a diameter in the range of 10-30 $\mathrm{nm}$. The presence of $\mathrm{K}$ in the individual $\mathrm{KTiO}_{x}$ nanowires was confirmed by STEM-based EDX mapping. Quantitative analysis yielded a K-concentration of about $4.5 \pm 1.1 \mathrm{wt} \%$.

Figure 3 shows the result of XRF measurements for the $\mathrm{KOH}$ treated $\mathrm{Ti}$ particles as a function of the $\mathrm{K}$ content. With increasing $\mathrm{KOH}$ concentration from 0 to $15 \mathrm{~mol} / \mathrm{L}$, the incorporated amount of $\mathrm{K}$ increased linearly, whereas above the critical concentration $(>15 \mathrm{~mol} / \mathrm{L})$, the slope slightly flattens indicating that the incorporation of $\mathrm{K}$ in $\mathrm{KTiO}_{x}$ surface structure reaches a first saturation point and further incorporation of $\mathrm{K}$ becomes more difficult during the WCP. The K content measured in the sample of $15 \mathrm{~mol} / \mathrm{L} \mathrm{KOH}$ treated $\mathrm{Ti}$ was about $4.4 \pm 0.1 \mathrm{wt} \%$, which is in agreement with the STEM-EDX result of $4.5 \pm$ $1.1 \mathrm{wt} \%$.

\subsection{Analysis of the Surface Area of $\mathrm{KTiO}_{x}$ Nanostructures}

BET analysis was performed in order to measure the increase of the surface area. The surface area profile is presented in Figure 4 as a function of concentration of the $\mathrm{KOH}$ solutions. The surface area gradually increased with the $\mathrm{KOH}$ concentration in agreement with the SEM results (Fig. 1), where the structural evolution from individual thick and short nanostructures to three-dimensional network of thin and elongated nanowires was observed. Accordingly, we can conclude that the WCP induced strong morphology changes with the $\mathrm{KOH}$ concentration. These changes effectively go together with an enlargement of the surface area.

\subsection{Analysis of Surface Charge of $\mathrm{KTiO}_{x}$ Nanostructures}

Figure 5 shows the zeta potential measured for the $15 \mathrm{~mol} / \mathrm{L} \mathrm{KOH}$ treated $\mathrm{Ti}$ particles in various $\mathrm{pH}$ levels. For $\mathrm{TiO}_{2}$ particles, previous studies reported that the isoelectric point (IEP) ranged from 5.1 to 6.7 , and the surface potential was rather positive. ${ }^{28-31}$ In contrast, the surface potential of the $\mathrm{KTiO}_{x}$ is negative and the IEP for $15 \mathrm{~mol} / \mathrm{L}$ $\mathrm{KOH}$ treated $\mathrm{Ti}$ particles is about 4.0. This is attributed to the formation of $\mathrm{OH}$ groups on the surface during the WCP. These $\mathrm{OH}$ groups can be a source of the negative charge observed and influence the electronegativity of the materials ions. ${ }^{32,33}$ It has to be noted that the $\mathrm{KTiO}_{x}$ nanowires show a large $\mathrm{pH}$ region of negatively charged surface, which is a valuable characteristic to conjugate the organic dyes without additional treatments.

\subsection{Analysis of the Crystalline Structure of $\mathrm{KTiO}_{x}$}

For $\mathrm{TiO}_{2}$, the anatase phase is known to be more photocatalytically active compared with the rutile phase. ${ }^{34}$ Especially for nanoscale $\mathrm{TiO}_{x}$, the formation of the anatase phase seems to be promoted due to the lower surface free energy. ${ }^{35}$ The transition from anatase to rutile phase is within the range of $400-1200{ }^{\circ} \mathrm{C} .{ }^{36}$ In order to study the effect of crystalline structure, the samples were annealed at temperatures between 300 to $750{ }^{\circ} \mathrm{C}$. The annealing didn't lead to any significant change in the particles size or shape. Also in terms of dispersion, the annealed particles didn't show any difference. Figure 6(a) shows surface morphologies of $\mathrm{KTiO}_{x}$ nanowires after annealing at different temperatures observed by SEM. As can be seen, the annealing has no significant effect below $600{ }^{\circ} \mathrm{C}$, and $\mathrm{KTiO}_{x}$ nanostructures showed similar diameters of about $30 \mathrm{~nm}$. In contrast, the nanowires annealed at $750{ }^{\circ} \mathrm{C}$ yielded much larger diameter of approximately $100 \mathrm{~nm}$. Figure 6(b) shows XRD spectra obtained from the Ti spheres containing $\mathrm{KTiO}_{x}$ nanowires annealed at different temperatures. For all spectra, the most predominant peaks originate from the Ti core. The peaks corresponding to $\mathrm{KTiO}_{x}$ are hardly visible in the WCP material as well 

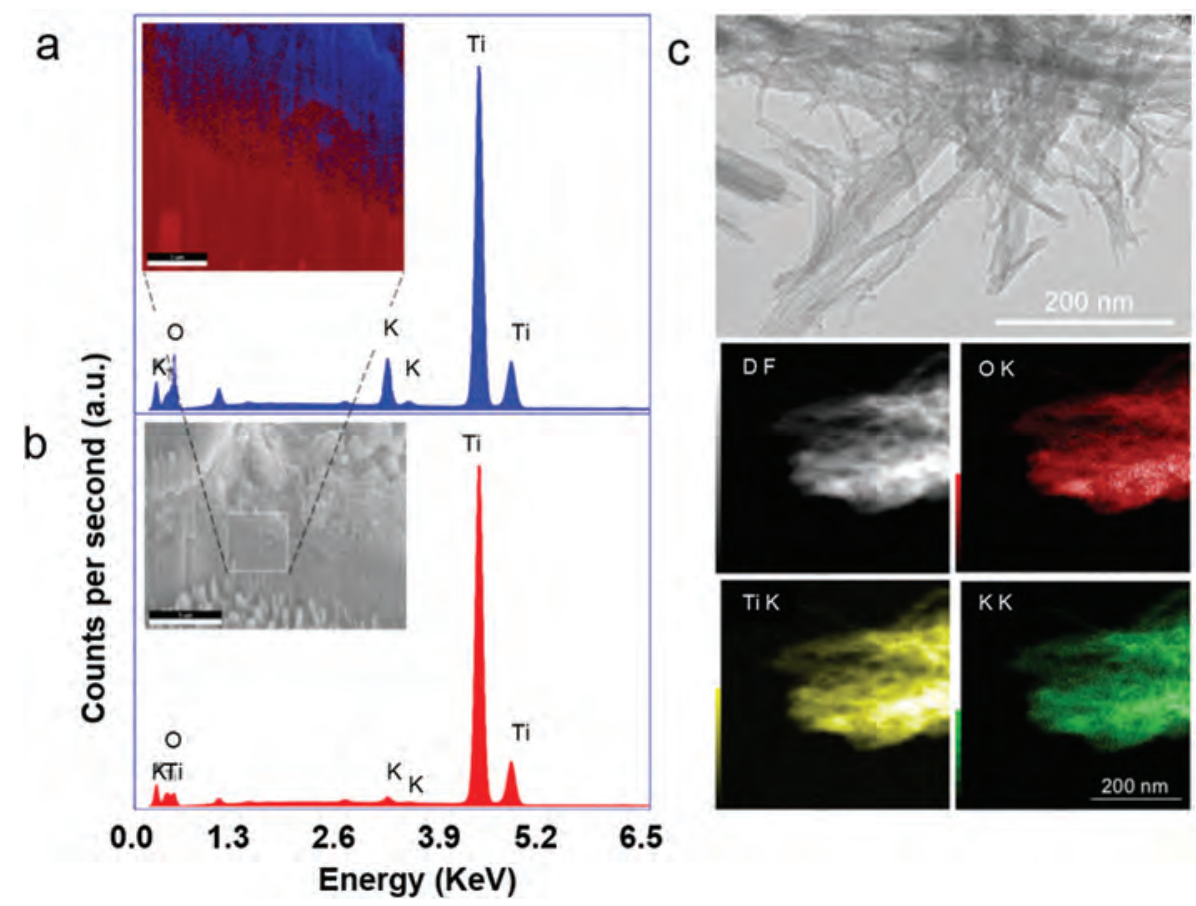

Figure 2. SEM-EDX spectra taken from the cross-sectional interface between (a) the $\mathrm{KTiO}_{x}$ shell and (b) the Ti core. The corresponding SEM image can be seen in the inset of (b) whereas the inset of (a) shows the EDX map of the interface area marked by white rectangle in the SEM image. The color-code matches with the color of the EDX spectra: K-rich and K-poor areas are colored blue and red, respectively. (c) TEM image of KTiO nanowires present in the outer shell-area of the Ti particle. The dark-field STEM image (DF) and the EDX-maps (O-, K- and Ti-maps) taken from the nanowires evidence the presence of $\mathrm{KTiO}_{x}$.

as in the samples annealed below $600{ }^{\circ} \mathrm{C}$. For the sample annealed at $600{ }^{\circ} \mathrm{C}$ small peaks appear. Finally after annealing at $750{ }^{\circ} \mathrm{C}$, peaks corresponding to the anatase and the rutile phases can clearly be identified, as indicated in Figure 6(b). In a detailed analysis, the peaks observed at $27.8^{\circ}, 41.75^{\circ}$ and $48.24^{\circ}$ could be correlated with (110) and (111) peaks of the rutile phase and (200) peak of the anatase phase, respectively.

$\mathrm{KTiO}_{x}$ nanowires annealed at different temperatures were investigated by high-resolution TEM. In Figure 7,

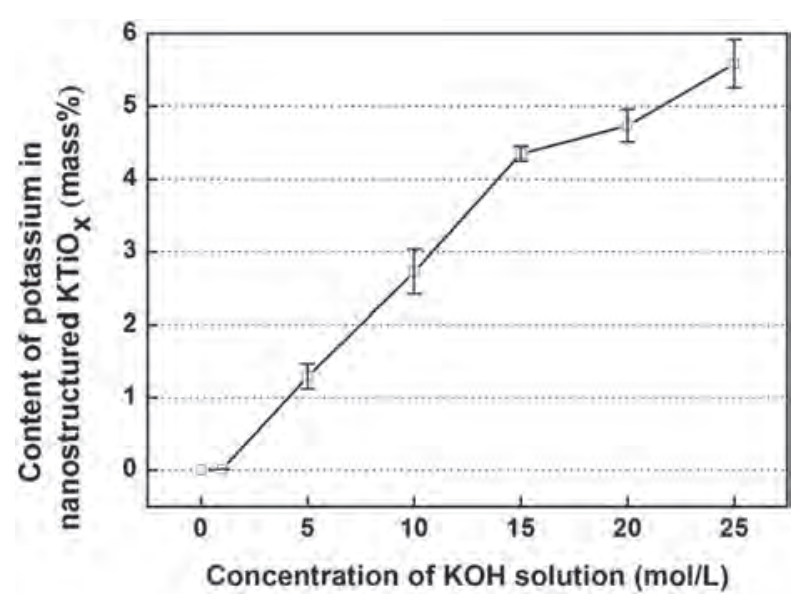

Figure 3. XRF measurements revealing the potassium content in the nanostructured $\mathrm{KTiO}_{x}$ obtained after $\mathrm{KOH}$ treatments of Ti particles with different concentrations. those annealed at $600{ }^{\circ} \mathrm{C}$ and $750{ }^{\circ} \mathrm{C}$ are presented. As can be seen in Figure 7(b), the nanowires annealed at $600{ }^{\circ} \mathrm{C}$ contain well-crystallized structure with lattice fringes appearing parallel with the nanowire axis. The spacing of the fringes was about $0.85 \mathrm{~nm}$ as also confirmed by the Fast-Fourier-Transform (FFT) pattern in Figure 7(c). Perpendicular to the nanowire axis, a lattice spacing of $0.36 \mathrm{~nm}$ was measured, which is in agreement with $d_{(101)}$ of the $\mathrm{TiO}_{2}$ anatase phase. The large $d$ spacing

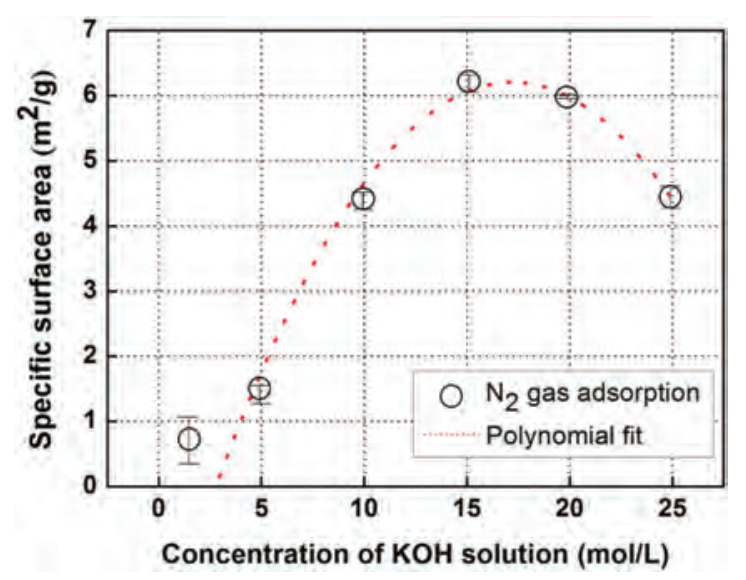

Figure 4. Surface areas of $\mathrm{KOH}$ treated $\mathrm{Ti}$ particles derived from BET analysis. By increasing $\mathrm{KOH}$ concentration, the surface area of $\mathrm{KTiO}_{x}$ increased. A maximum surface area was achieved at $15 \mathrm{~mol} / \mathrm{L}$ with a specific surface area of about $6.1 \mathrm{~m}^{2} / \mathrm{g}$.

J. Nanosci. Nanotechnol. 18, 1-9, 2018 


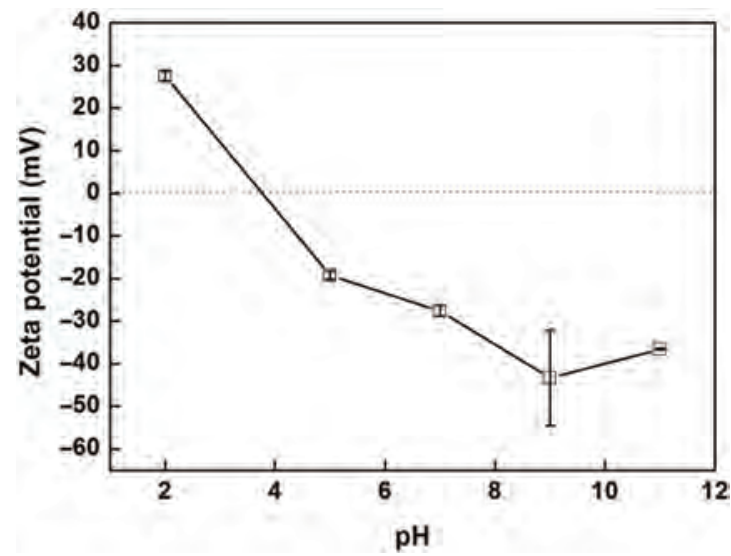

Figure 5. Zeta potential measured for the $15 \mathrm{~mol} / \mathrm{L} \mathrm{KOH}$ treated $\mathrm{Ti}$ particles as a function of $\mathrm{pH}$.

of about $0.85 \mathrm{~nm}$ does not correspond to any plane in the anatase or rutile crystal structures. However, potassium titanates are well known to form a layered or tunnel structure by zig-zag layers of titanium-oxygen octahedra separated by $\mathrm{K}_{2} \mathrm{O} .{ }^{37}$ The obtained value is close to that previously reported for $\mathrm{K}_{0.06} \mathrm{TiO}_{2}(0.72 \mathrm{~nm})^{38}$ or $\mathrm{K}_{2} \mathrm{Ti}_{8} \mathrm{O}_{17}$ $(0.78 \mathrm{~nm}) .{ }^{39}$

For samples annealed at lower temperatures, similar high-resolution TEM images were obtained but the lattice fringes were less well pronounced indicating that the crystallinity improved with the annealing temperature. However, annealing at $750{ }^{\circ} \mathrm{C}$ leads to the formation of crystallites with a diameter of a few $\mathrm{nm}$ on the nanowire surface. In the core-region, the wide-spaced lattice fringes remain. In the FFT pattern (Fig. 7(f)), a series of diffraction spots arranged in concentric rings can be seen. They could be matched with $d_{(111)}$ and $d_{(211)}$ of the rutile phase. EDX analysis revealed a slightly reduced K-concentration. The structural transformation from the layered structure to rutile structure may be promoted by the loss of $\mathrm{K}$ atoms.

\subsection{Photocatalytic Activity of the KTiO $_{x}$ Nanostructures}

\subsubsection{Effect of the Surface Area}

Generally, the photocatalytic activity leading to degradation of dyes depends on the catalyst concentration. The high surface area exerts a synergistic effect on catalyst concentration. Since the higher catalyst concentration induces an increase of the adsorbed dye molecules, higher photocatalytic performance can be expected. ${ }^{30}$ In order to evaluate the photocatalytic activity, we monitored the degradation of MB dyes upon UV irradiation. Figure 8(a) shows the effect of the WCP on photocatalytic degradation of MB. The Ti particles treated with $15 \mathrm{~mol} / \mathrm{L} \mathrm{KOH}$ solution, which has the highest surface area (see Fig. 4), yielded significantly higher photocatalytic efficiency. The UV-Vis absorption results shown in Figure 8(b) clearly confirm this trend: The characteristic absorption intensity of MB dye at $664 \mathrm{~nm}$ decreased under UV irradiation, indicating the dye degradation. The $15 \mathrm{~mol} / \mathrm{L} \mathrm{KOH}$ treated Ti particles showed remarkable photocatalytic degradation of MB dye with approximately $90 \%$ degradation upon 2 hours of UV light exposure, compared to $50 \%$ and $40 \%$ degradation for the $1 \mathrm{~mol} / \mathrm{L} \mathrm{KOH}$ treated Ti particles and raw Ti particles, respectively. Taking the BET analysis (see Fig. 3) into account, where the surface area of $15 \mathrm{~mol} / \mathrm{L}$ $\mathrm{KOH}$ treated $\mathrm{Ti}$ particles was about 8 times higher than that of the $1 \mathrm{~mol} / \mathrm{L} \mathrm{KOH}$ treated Ti particles, it can be concluded that the enhanced photocatalytic activity directly
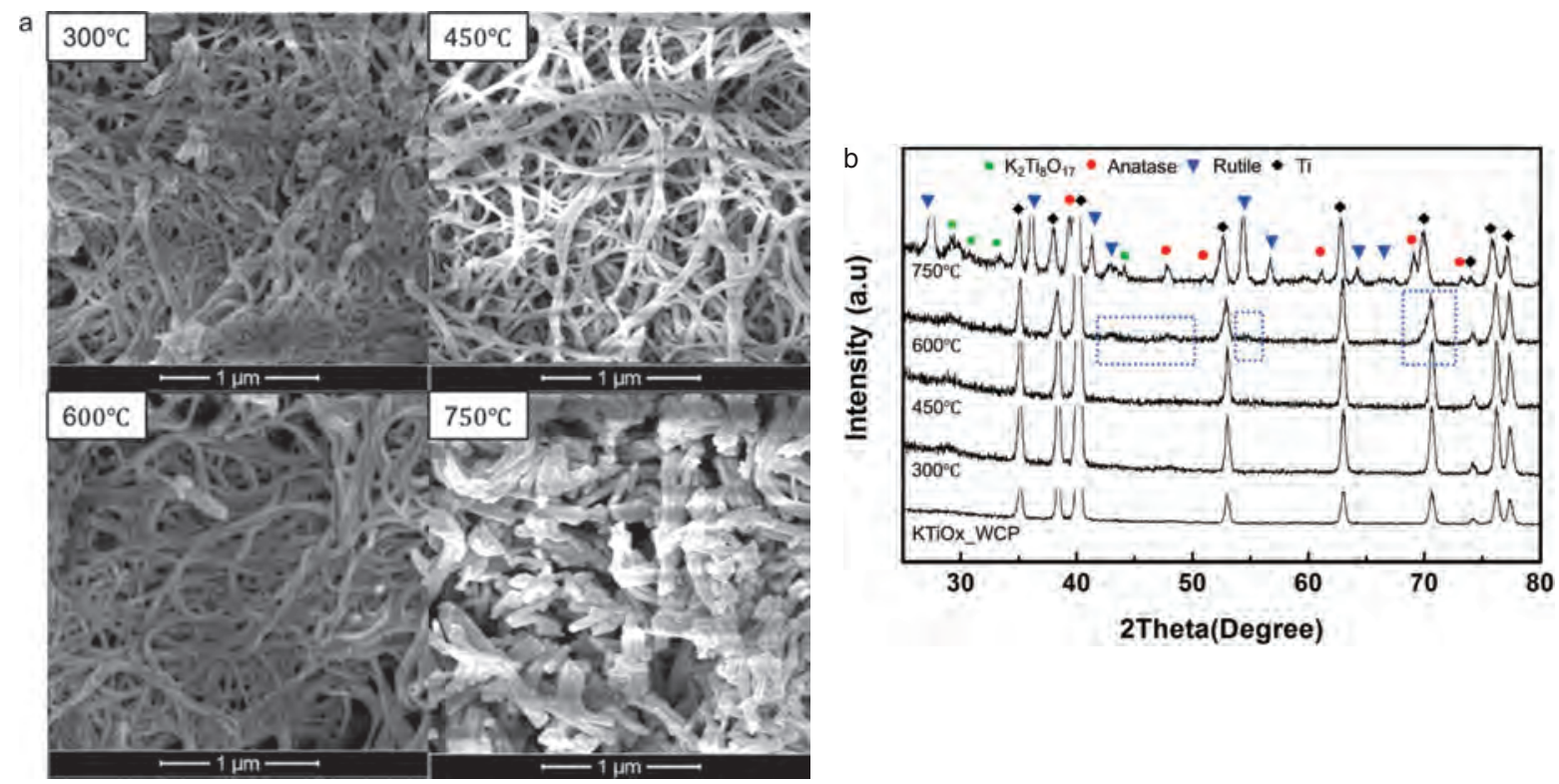

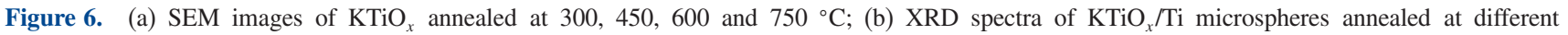
temperatures. The peaks corresponding to the anatase and the rutile phases are marked with spheres and triangles. 

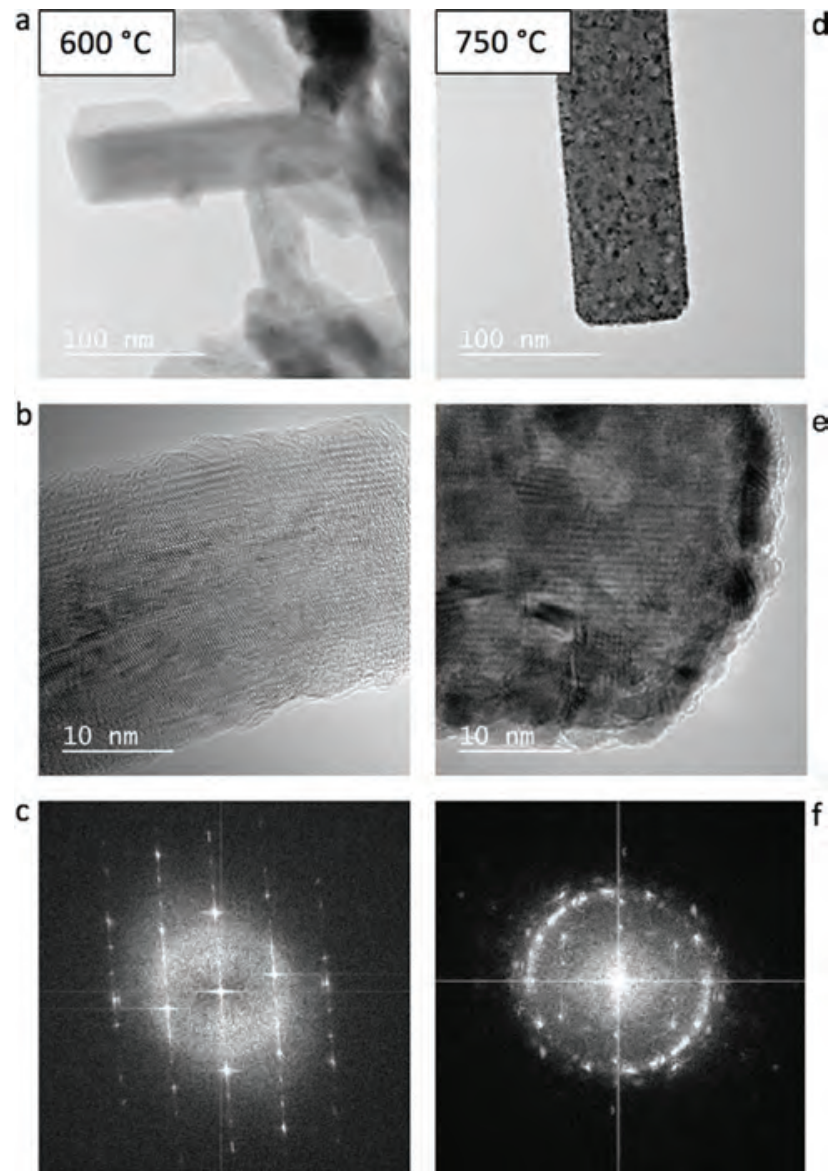

Figure 7. (a, b) TEM images of $\mathrm{KTiO}_{x}$ annealed at $600{ }^{\circ} \mathrm{C}$ show that the nanowires are crystalline with well-defined layered structure with a spacing of about $0.8 \mathrm{~nm}$. (d, e) TEM images of $\mathrm{KTiO}_{x}$ annealed at $750{ }^{\circ} \mathrm{C}$ reveal crystallites of a few nanometer in size, which give the nanowire speckled contrast. The respective FFT patterns ( $c$ and f) confirm the crystalline structure. The diffraction spots arranged in concentric rings in (f) can be matched with lattice spacings of the $\mathrm{TiO}_{2}$ rutile structure.

correlates with the increased surface area, in agreement with previous reports. ${ }^{6,40}$ This photodegradation efficiency of the produced $\mathrm{KTiO}_{x}$ can also be determined quantitatively based on the evolution of the peak height at $664 \mathrm{~nm}$, using the pseudo-first order model as follows: ${ }^{41}$

$$
\ln \left(C_{0} / C_{t}\right)=k t
$$

where $C_{0}$ and $C_{t}$ are the concentrations of dye at the time $t=0$ and time $t$, respectively, and $k$ is the pseudofirst order rate constant. As presented in Table I, the $15 \mathrm{~mol} / \mathrm{L} \mathrm{KOH} \mathrm{Ti}$ particles with the highest surface area revealed a $C / C_{0}$ ratio of 0.09 , which is significantly lower than that of the untreated sample with 0.87 , indicating the high degree of degradation. Also compared with pure $\mathrm{TiO}_{2}$ particles of the same size, the $C / C_{0}$ ratio is about eight times smaller. This result clearly confirms the role of the high surface area leading to high photocatalytic efficiency.
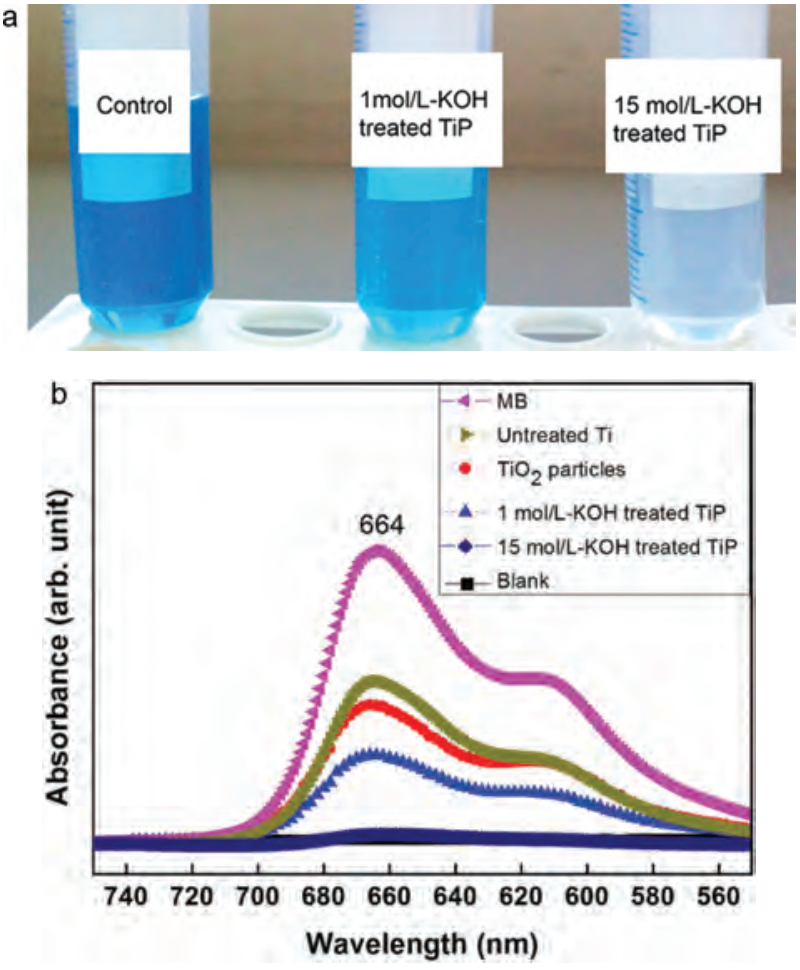

Figure 8. (a) Photographs and (b) UV-Vis absorption spectra taken from the original $\mathrm{MB}$ dye, and from the dye exposed to $\mathrm{KOH}$ treated Ti particles after UV light irradiation for 2 hours. UV-Vis spectra of untreated Ti particles as well as oxidized Ti particles $\left(\mathrm{TiO}_{2}\right.$ particles $)$ are also included for comparison.

\subsubsection{Effect of the Surface Charge}

Additionally, the effect of surface charge on the photocatalytic activity and the photodegradation of MB dye was studied by varying the $\mathrm{pH}$ values (acidic, neutral and alkaline solutions). Figure 9 shows the different decolorization of MB dye after treatment with the $15 \mathrm{~mol} / \mathrm{L} \mathrm{KOH}$ treated $\mathrm{Ti}$ particles of different $\mathrm{pH}$, representatively. As can be seen in Figure 9(a), the decolorizing is more significant for $\mathrm{pH}=7.0$ and 10.0 compared with $\mathrm{pH}=2.5$. In order to look at this result more into detail, UV-Vis absorption spectra were taken as a function of $\mathrm{pH}$ (see Fig. 9(b)). In alkaline environment, the degradation was about $95 \%$, indicating the strong effect of the $\mathrm{pH}$ level. In contrast, for $\mathrm{pH}=2.5$, the degradation was almost not negligible compared with that of the raw MB dye. In order to exclude the formation of the colorless leuco-methylene blue, we

Table I. Values of $C / C_{0}$ with different WCP conditions and $\mathrm{TiO}_{2}$ particles after UV light irradiation for $2 \mathrm{~h}$.

\begin{tabular}{lc}
\hline Samples & $C / C_{0}($ after 2 h) \\
\hline $\mathrm{MB}$ & 0.98 \\
Untreated & 0.87 \\
$\mathrm{TiO}_{2}$ particles & 0.75 \\
$1 \mathrm{~mol} / \mathrm{L} \mathrm{KOH}$ treated $\mathrm{Ti}$ & 0.54 \\
$15 \mathrm{~mol} / \mathrm{L} \mathrm{KOH}$ treated $\mathrm{Ti}$ & 0.09 \\
\hline
\end{tabular}



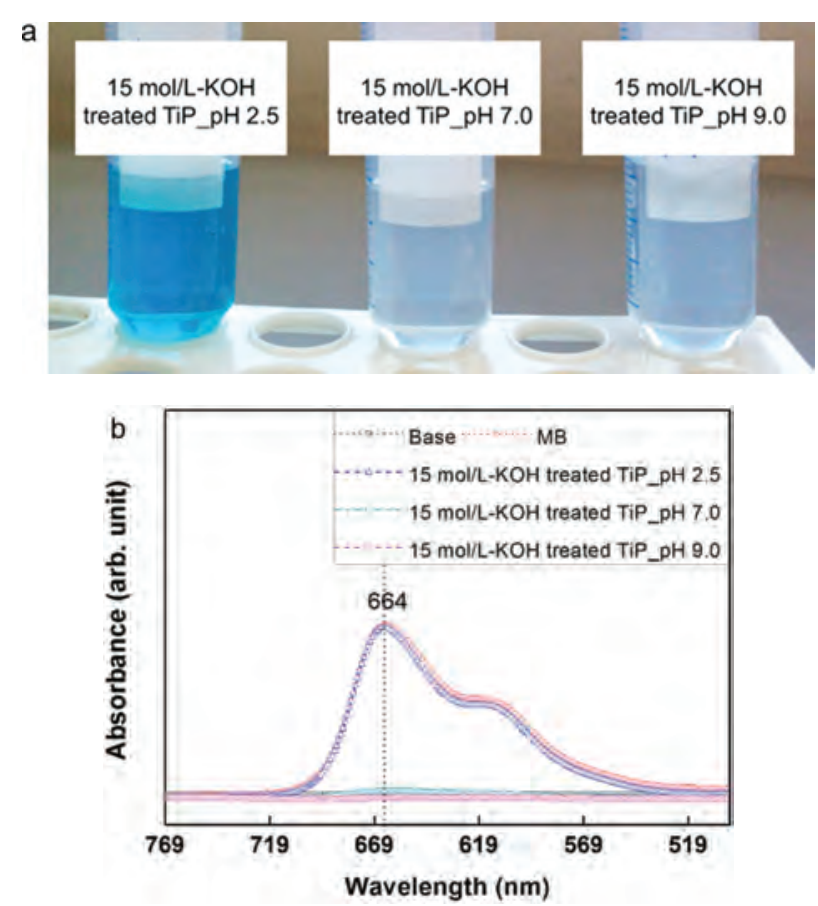

Figure 9. (a) Photographs taken from of MB dye solutions treated with $\mathrm{KTiO}_{x}$ of different surface charge and (b) UV-Vis absorption spectra of $\mathrm{MB}$ dye solution and $15 \mathrm{~mol} / \mathrm{L} \mathrm{KOH}$ treated Ti particles at $\mathrm{pH} 2.5,7.0$, and 9.0 after 2 hours of UV light exposure.

carefully checked the UV-Vis spectra but its characteristic absorption peak at around $310 \mathrm{~nm}$ (not shown) couldn't be observed.

Generally, $\mathrm{pH}$ is one of the most important parameters for the photocatalytic activity because $\mathrm{pH}$ strongly determines the adsorption of molecules onto the catalysts surface. ${ }^{17}$ Strong adsorption of the degradable molecules is a prerequisite for the enhancement of the photocatalytic activity. MB dye molecules are known to be cationic. Consequently, negative sites on the surface of catalyst can promote the adsorption of molecules owing to electrostatic interactions. As observed in zeta-potential measurements (Fig. 5), the surface of $\mathrm{KTiO}_{x}$ was charged positively in acidic media below IEP $(<\mathrm{pH} 4)$ and negatively charged above IEP ( $>$ pH 4). Hence, below IEP, the electrostatic repulsion between $\mathrm{MB}$ dye molecules and the positively charged catalyst surface will retard their adsorption and hamper the photocatalytic activity. On the other hand, the strong adsorption between MB dye molecules and negatively charged surface will occur above IEP, resulting in enhanced photocatalytic effect.

The photocatalytic process is based on the generation of electron-hole pairs under UV irradiation, which affects the adsorption-desorption processes and the separation of the photo-generated electron-hole pairs in the surface of the catalyst particles. ${ }^{17}$ When a semiconductor absorbs light of energy greater or equal to its band gap, electrons are excited into the conduction band and holes are existed into the valence band. This charge separation induces the formation of electron-hole pairs which can generate free radicals such as hydroxyl $(\cdot \mathrm{OH})$. Active species such as ${ }^{\circ} \mathrm{OH}$ are very efficient oxidizers of organic dyes, leading to dye fading as shown in Figures 8(a) and $9(\mathrm{a}){ }^{42,43}$ Above IEP, hydroxide ions $\left(\mathrm{OH}^{-}\right)$induce the generation of hydroxyl radicals ${ }^{\circ} \mathrm{OH}$, which originate from the photo-induced oxidation of $\mathrm{OH}^{-}$by holes forming on the $\mathrm{KTiO}_{x}$ surface. Overall, $\mathrm{pH}$ strongly affects the adsorption-desorption process and the generation of oxidizer species. Therefore, the degradation efficiency of dyes increases with the $\mathrm{pH}$ value owing to the electrostatic interaction between $\mathrm{MB}$ dye cations and the negative surface of $\mathrm{KTiO}_{x}$.

\subsubsection{Effect of the Annealing Temperature and Different Dyes}

The photocatalytic degradation of $\mathrm{MB}, \mathrm{CG}$ and $\mathrm{AR}$ dye solutions was studied as a function of the annealing temperature. Figure 10(a) shows the photocatalytic performance of different $\mathrm{KTiO}_{x}$ samples in the MB dye solution. After 2 hours of UV treatment, the $\mathrm{KTiO}_{x}$ annealed at $600{ }^{\circ} \mathrm{C}$ showed significantly higher degradation compared with the reference sample of $\mathrm{KTiO}_{x}$ obtained without annealing. The trend is clearly visible: the photocatalytic efficiency increases with the annealing temperature. However, the $\mathrm{KTiO}_{x}$ sample annealed at $750{ }^{\circ} \mathrm{C}$ does not follow this trend, and the degradation efficiency drops even below that of pristine $\mathrm{KTiO}_{x}$ reference sample. This can be explained, on the one hand, by the reduced surface area due to the larger diameter of nanowires as well as due to the more entangled nanostructures. On the other hand, annealing at $750{ }^{\circ} \mathrm{C}$ promotes the formation of the rutile phase (see Fig. 7), which is known to have a lower density of localized states and to lead to faster charge carrier recombination. ${ }^{44}$

For the CG dye solution, outstanding degradation efficiency, even higher than that of MB dye, was observed, as presented in Figure 10(b). All $\mathrm{KTiO}_{x}$ showed a degradation efficiency higher than $95 \%$ under 1 hour UV exposure. The $\mathrm{KTiO}_{x}$ annealed at $450{ }^{\circ} \mathrm{C}$ showed the best performance. In the case of AR dye solution, the photocatalytic performance is generally rather low. The $\mathrm{KTiOx}$ annealed at $600{ }^{\circ} \mathrm{C}$ yielded the highest degradation efficiency of about $32.9 \%$.

\subsubsection{Recovery and Re-Use of $\mathrm{KTiO}_{x}$}

For $\mathrm{TiO}_{2}$ nanostructures, their separation from aqueous suspension is a major constraint in photocatalytic waste water treatment. The separation is generally energyintensive as well as cumbersome, and it also does not reach the high recovery efficiency. This aspect remains a serious drawback for potential practical applications. ${ }^{36}$

To analyze the recovery and re-use performance of $\mathrm{KTiO}_{x}$, those particles annealed at $600{ }^{\circ} \mathrm{C}$ were studied as their all-round performances in $\mathrm{MB}, \mathrm{CG}$, and $\mathrm{AR}$ 

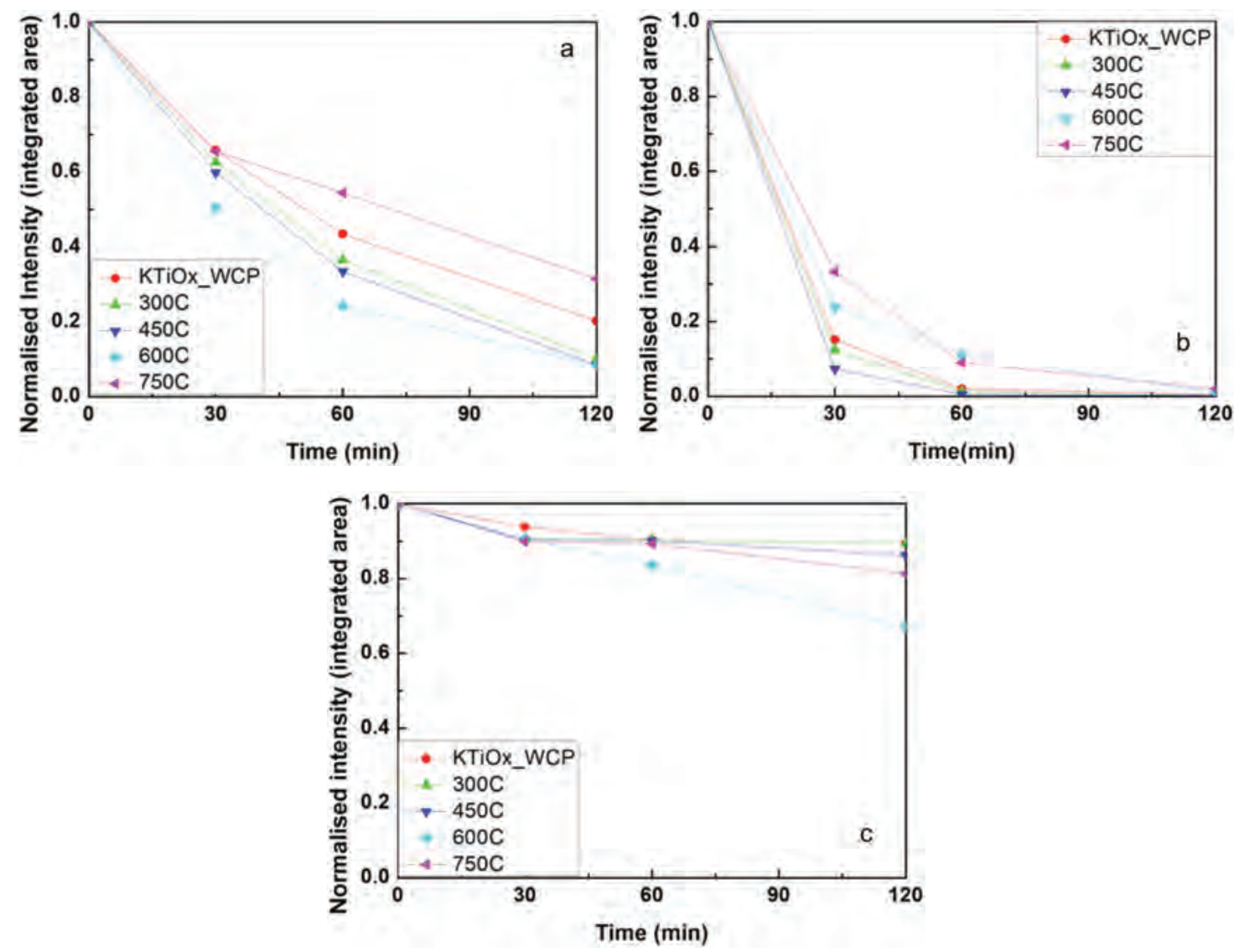

Figure 10. Photocatalytic degradation behaviors of (a) MB dye, (b) CG dye, and (c) AR dye solution treated with $\mathrm{KTiO}_{x} / \mathrm{Ti}$ particles annealed at different temperatures.

dye solutions were high. The recovered $\mathrm{KTiO}_{x}$ was reused for photocatalysis up to four times. Figure 11 displays the evolution of the degradation efficiency as a function of the number of cycles. In the case of $\mathrm{MB}$ dye, the $\mathrm{KTiO}_{x}$ could easily be cleaned by only deionized water and organic solvents (ethanol and isopropanol) without any other additional processes, especially without additional UV treatment for several hours as reported by

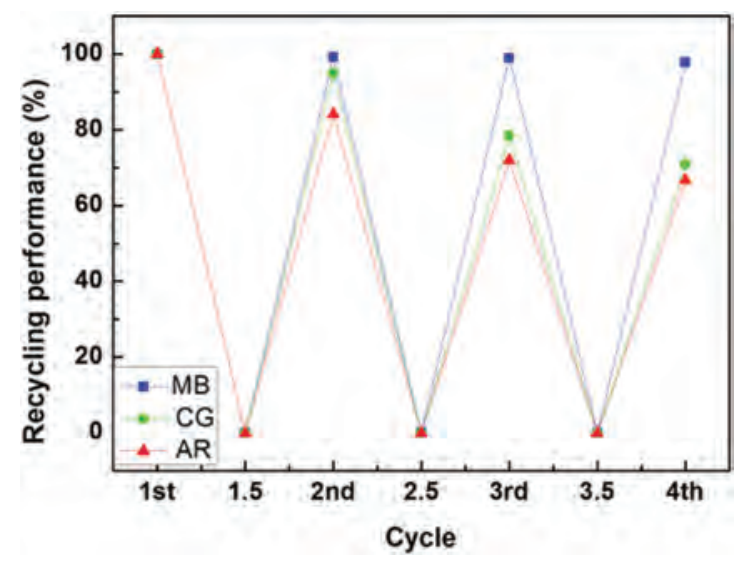

Figure 11. The degradation efficiency variation after UV irradiation cycles in repeated experiments.
Kumar et al. ${ }^{45}$ The photocatalytic performance remained almost constant up to about $97 \%$ after several cycles. Comparable repeatability has been reported for $\mathrm{TiO}_{2}$ nanotubes fixed on Ti substrate. ${ }^{46}$

The reusability of $\mathrm{TiO}_{2}$ in $\mathrm{CG}$ and $\mathrm{AR}$ dye has not been reported much in literature. In our cycled experiments, the photocatalytic performance in the CG dye was reduced to about $71 \%$ after 3 cycles. In the AR dye solution, the recycle performance was further weakened to about $67 \%$ degradation efficiency in the last cycle, even when additional cleaning via UV irradiation was performed. A possible explanation for this observation is that the organic residues remain attached inside the nanowire network structure and cannot easily be washed out. Why $\mathrm{CG}$ and AR dyes are more sensitive to the entrapment is not yet clear and requires more detailed analysis.

It has to be mentioned that the $\mathrm{KTiO}_{x}$ nanostructures produced by the WCP of Ti microspheres enable immobilization of the catalyst directly from the synthesis step. For supported $\mathrm{TiO}_{2}$, the photochemical reactivity is normally reduced due to the reduction of active surface area and the inactive support hindrance in light harvesting. These implications do not occur for the $\mathrm{KTiO}_{x}$ nanostructures on $\mathrm{Ti}$ microspheres. Moreover, the attachment of $\mathrm{KTiO}_{x}$ on $\mathrm{Ti}$ is mechanical strong in order to ensure a long term operation. 
Together with the simple cleaning procedure (using only water and organic solvents without additional UV irradiation) and the remarkably efficient recycling performance in $\mathrm{MB}, \mathrm{KTiO}_{x}$ produced by the WCP has a high potential for re-usable photocatalyst.

\section{CONCLUSIONS}

We performed a detailed structural and chemical analysis of $\mathrm{KTiO}_{x}$ nanostructures produced by the WCP of Ti microspheres. Their photocatalytic activity was studied as a function of the surface area as well as the surface charge. The $\mathrm{KTiO}_{x}$ nanowires obtained from $15 \mathrm{~mol} / \mathrm{L} \mathrm{KOH}$ solution yielded the highest surface area and also the highest photocatalytic performance. The negatively charged $\mathrm{KTiO}_{x}$ nanostructures which were annealed at $600{ }^{\circ} \mathrm{C}$ showed the highest photocatalytic degradation of $92 \%$ for MB dye, 99\% for CG dye, and $33 \%$ for AR dye. This result was attributed to the enhanced active surface area and surface charge as well as the presence of the crystalline layered structure based on the anatase phase. In addition, the $\mathrm{KTiO}_{x}$ nanostructures immobilized on $\mathrm{Ti}$ particles offer great advantages for separation from the liquid. Indeed, remarkable recycling performance of $97 \%$ for $\mathrm{MB}$ dye, $71 \%$ for CG dye, and $67 \%$ AR dye was obtained after simply washing with deionized water and with organic solvents. We believe that the $\mathrm{KTiO}_{x}$ nanostructures produced by the WCP has a great potential for photocatalysis but also for photovoltaics, bio-and eco-friendly devices, where high catalytic activity and easy cleaning are required.

Acknowledgments: We thank Professor Lutz Mädler for his help and the access to his facilities. This work was supported by the Belgian Hercules Stichting (HER/08/25 and AKUL/13/19) as well as by the Flemish FWO with Odysseus program, the bilateral collaboration project with Korea (VS.039.16N) and FWO research project G0B8915N. We are also grateful to the Research Council of KU Leuven for the project IOF-KP (3E140382).

\section{References and Notes}

1. N. Toshima and T. Yonezawa, New J. Chem. 22, 1179 (1998).

2. R. Narayanan and M. A. El-Sayed, Nano Lett. 4, 1343 (2004).

3. J. Grunes, J. Zhu, M. Yang, and G. A. Somorjai, Catal. Lett. 86, 157 (2003).

4. L. E. E. Greene, B. D. D. Yuhas, M. Law, D. Zitoun, and P. Yang, Inorg. Chem. 45, 7535 (2006).

5. L. G. Devi and R. Kavitha, Appl. Catal. B Environ. 140, 559 (2013).

6. W. Y. Teoh, J. A. Scott, and R. Amal, J. Phys. Chem. Lett. 3, 629 (2012).

7. M. N. Chong, B. Jin, C. W. K. Chow, and C. Saint, Water Res. 44, 2997 (2010).

8. K. Hashimoto, H. Irie, and A. Fujishima, Jpn. J. Appl. Phys. 191 (2005).

9. Y. Ma, X. L. Wang, Y. S. Jia, X. B. Chen, H. X. Han, and C. Li, Chem. Rev. 114, 9987 (2014).
10. I. M. Arabatzis and P. Falaras, Nano Lett. 3, 2 (2002).

11. M. K. Seo and S. J. Park, J. Nanosci. Nanotechnol. 11, 4633 (2011).

12. H. He, A. Chen, M. Chang, L. Ma, and C. Li, J. Ind. Eng. Chem. 19, 1112 (2013)

13. L. Chen, Y. Man, and Z. Chen, Nanotechnology 25, 165401 (2014)

14. S. Y. Chae, M. K. Park, S. K. Lee, T. Y. Kim, S. K. Kim, and W. I. Lee, Chem. Mater. 15, 3326 (2003)

15. K. Nagaveni, G. Sivalingam, M. S. Hegde, and G. Madras, Environ Sci. Technol. 38, 1600 (2004).

16. Z. B. Zhang, C. C. Wang, R. Zakaria, and J. Y. Ying, J. Phys. Chem. B 102, 10871 (1998)

17. A. Franco, M. C. Neves, M. M. L. R. Carrott, M. H. Mendonça, M. I Pereira, and O. C. Monteiro, J. Hazard. Mater. 161, 545 (2009).

18. J. Jaramillo, B. A. Garzón, and L. Tirado Mejía, J. Phys.: Conf. Ser 687, 12099 (2016).

19. S. Y. Lee, C. H. Lee, D. Y. Kim, J. Locquet, and J. W. Seo, Nanomaterials 5, 1397 (2015).

20. L.-C. Chen, C.-M. Huang, and F.-R. Tsai, J. Mol. Catal. A Chem. 265, 133 (2007)

21. Y. Bessekhouad, D. Robert, J. V. Weber, and N. Chaoui, J. Photochem. Photobiol. A Chem. 167, 49 (2004).

22. G. Yang, Z. Yan, T. Xiao, and B. Yang, J. Alloys Compd. 580, 15 (2013).

23. S. Y. Lee, M. Takai, H. M. Kim, and K. Ishihara, Curr. Appl. Phys. 9, e266 (2009).

24. S. Y. Lee, R. Matsuno, K. Ishihara, and M. Takai, Appl. Phys. Express 4, 1 (2011)

25. E. Shin, S. Jin, J. Kim, S. J. Chang, B. H. Jun, K. W. Park, and J. Hong, Appl. Surf. Sci. 379, 33 (2016).

26. E. Shin, S. Jin, and J. Hong, Appl. Surf. Sci. 416, 353 (2017).

27. S. Y. Lee, R. Matsuno, K. Ishihara, and M. Takai, Biosens. Bioelectron. 41, 289 (2013).

28. J. Augustynski, Electrochim. Acta 38, 43 (1993).

29. G. D. Parfitt, Prog. Surf. Membr. Sci. 11, 181 (1976)

30. T. Yoko, L. Hu, H. Kozuka, and S. Sakka, Thin Solid Films 283, 188 (1996).

31. A. Di Paola, G. Marcí, L. Palmisano, M. Schiavello, K. Uosaki, S. Ikeda, and B. Ohtani, J. Phys. Chem. B 106, 637 (2002)

32. K. Tanaka and A. Ozaki, J. Catal. 8, 1 (1967).

33. M. Misono, E. Ochiai, Y. Saito, and Y. Yoneda, J. Inorg. Nucl. Chem. 29, 2685 (1967)

34. K. Hashimoto, H. Irie, and A. Fujishima, Jpn. J. Appl. Phys. 4, 8269 (2005).

35. H. Zhang and J. F. Banfield, J. Mater. Chem. 8, 2073 (1998).

36. J. Sun, Y. Wang, R. Sun, and S. Dong, Mater. Chem. Phys. 115, 303 (2009).

37. J. F. Banfield and D. R. Veblen, Am. Mineral. 77, 545 (1992).

38. Y. Takahashi, N. Kijima, and J. Akimoto, Chem. Mater. 18, 748 (2006).

39. H. Wang, C. C. Oey, A. B. Djurišiæ, M. H. Xie, Y. H. Leung, K. K Y. Man, W. K. Chan, A. Pandey, J. M. Nunzi, and P. C. Chui, Appl. Phys. Lett. 87 (2005)

40. S. Linic, P. Christopher, and D. B. Ingram, Nat. Mater. 10, 911 (2011).

41. J.-M. Herrmann, H. Tahiri, Y. Ait-Ichou, G. Lassaletta, A. R. González-Elipe, and A. Fernadez, Appl. Catal. B Environ. 13, 219 (1997).

42. C. L. Torres-Martínez, R. Kho, O. I. Mian, and R. K. Mehra, J. Colloid Interface Sci. 240, 525 (2001).

43. H. R. Pouretedal, A. Norozi, M. H. Keshavarz, and A. Semnani, J. Hazard. Mater. 162, 674 (2009).

44. D. A. H. Hanaor and C. C. Sorrell, J. Mater. Sci. 46, 855 (2011)

45. S. Kumar, D. K. Lodhi, and J. P. Singh, RSC Adv. 6, 45120 (2016).

46. S. Yuan, L. Yu, L. Shi, J. Wu, J. Fang, and Y. Zhao, Catal. Commun. 10, 1188 (2009).

Received: 10 October 2017. Accepted: 11 January 2018. 